\title{
Demyelination of the Brain Is Associated with Methionine Adenosyltransferase I/III Deficiency
}

\author{
Margaret E. Chamberlin, ${ }^{\star}$ Tsuneyuki Ubagai, ${ }^{\star}$ S. Harvey Mudd, ${ }^{\ddagger}$ William G. Wilson, ${ }^{\S}$ James V. Leonard, \\ and Janice Yang Chou* \\ *Heritable Disorders Branch, National Institute of Child Health and Human Development, ${ }^{\ddagger}$ Laboratory of General and Comparative \\ Biochemistry, National Institute of Mental Health, National Institutes of Health, Bethesda, Maryland 20892; ${ }^{\circledR}$ University of Virginia

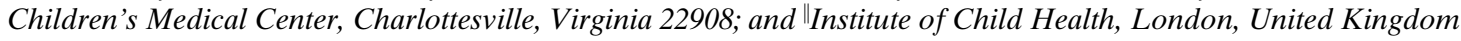

\begin{abstract}
Individuals deficient in hepatic methionine adenosyltransferase (MAT) activity (MAT I/III deficiency) have been demonstrated to contain mutations in the gene (MATA1) that encodes the major hepatic forms, MAT I and III. MAT I/III deficiency is characterized by isolated persistent hypermethioninemia and, in some cases, unusual breath odor. Most individuals with isolated hypermethioninemia have been free of major clinical difficulties. Therefore a definitive diagnosis of MAT I/III deficiency, which requires hepatic biopsy, is not routinely made. However, two individuals with isolated hypermethioninemia have developed abnormal neurological problems, including brain demyelination, suggesting that MAT I/III deficiency can be deleterious. In the present study we have examined the MATA1 gene of eight hypermethioninemic individuals, including the two with demyelination of the brain. Mutations that abolish or reduce the MAT activity were detected in the MATA1 gene of all eight individuals. Both patients with demyelination are homozygous for mutations that alter the reading frame of the encoded protein such that the predicted MAT $\alpha 1$ subunits are truncated and enzymatically inactive. The product of MAT, S-adenosylmethionine (AdoMet), is the major methyl donor for a large number of biologically important compounds including the two major myelin phospholipids, phosphatidylcholine and sphingomyelin. Both are synthesized primarily in the liver. Our findings demonstrate that isolated persistent hypermethioninemia is a marker of MAT I/III deficiency, and that complete lack of MAT I/III activity can lead to neurological abnormalities. Therefore, a DNA-based diagnosis should be performed for individuals with isolated hypermethioninemia to assess if therapy aimed at the prevention of neurological manifestations is warranted. (J. Clin. Invest. 1996. 98:1021-1027.) Key words: methionine adenosyltransferase deficiency • genetic mutations $\bullet$ brain demyelination
\end{abstract}

M.E. Chamberlin and T. Ubagai contributed equally to this work.

Address correspondence to Janice Yang Chou, NIH, Building 10, Room 9S241, Bethesda, MD 20892. Phone: 301-496-1094; FAX: 301402-7784.

Received for publication 9 May 1996 and accepted in revised form 21 June 1996.

J. Clin. Invest.

(C) The American Society for Clinical Investigation, Inc. 0021-9738/96/08/1021/07 \$2.00

Volume 98, Number 4, August 1996, 1021-1027

\section{Introduction}

Methionine adenosyltransferase (MAT, ATP:L-methionine S-adenosyltransferase, EC 2.5.1.6) ${ }^{1}$ catalyzes the biosynthesis of S-adenosylmethionine (AdoMet) from methionine and ATP (1). AdoMet is the major methyl donor for many of the transmethylation reactions in the body $(2,3)$. AdoMet also participates in the transsulfuration pathway and, after decarboxylation, serves as a propylamine group donor in the biosynthesis of polyamines. Three forms of MAT (I, II, and III) ${ }^{2}$ have been identified in mammalian tissues (4-8). MAT I and III, which are encoded by the single copy MATA1 gene, represent tetramers and dimers formed from identical $\alpha 1$ subunits and are synthesized primarily in the liver $(6,9,10)$. MAT II, encoded by a separate MATA2 gene $(11,12)$, is found in fetal liver (and to a lesser extent in adult liver) as well as in kidney, brain, testis, and lymphocytes $(7,8,11,12)$. The human MATA2 gene has been mapped to chromosome 2p11.2 (12).

Newborns are routinely screened for high levels of serum methionine as an indicator of hyperhomocyst(e)inemia associated with deficient cystathionine $\beta$-synthase activity (3). High serum methionine levels are also found in patients with tyrosinemia type I and liver diseases. A subset of children with high serum methionine have been found to have isolated persistent hypermethioninemia without any other metabolic abnormalities $(3,13)$. Several such individuals were diagnosed by enzyme studies as having deficient MAT activity in the liver (14-18). These MAT I/III deficient individuals have normal levels of MAT activity in their cultured skin fibroblasts, red blood cells, or lymphoid cells. To establish the molecular basis of MAT I/III deficiency, we have recently characterized the $M A T A 1$ gene of three such patients and demonstrated that all three individuals have lesions in their MATA1 gene (19).

Clinical outcomes in individuals with isolated persistent hypermethioninemia have been documented in relatively few patients and chiefly at young ages. It has been speculated that MAT I/III deficiency is not deleterious. However, Surtees et

1. Abbreviations used in this paper: AdoMet, S-adenosylmethionine; MAT, methionine adenosyltransferase; SSCP, single-strand conformation polymorphism.

2. In this paper we have adopted nomenclatures (M. Kotb, J. Mato, S.H. Mudd, J.Y. Chou and G.L. Cantoni, submitted for publication) that conform to the recommendations of the Genetic Nomenclature Guide (Stewart, A., Trends Genet. 1-43, 1995). The predominately liver expressed MATA1 gene encodes MAT I and III which represent tetramers and dimers, respectively, formed from identical $\alpha 1$ subunits. The separate, but highly homologous MATA2 gene is expressed in non-hepatic tissues, fetal liver, and to a low extent in adult liver. MAT I, II, and III correspond to enzymes previously named MAT $\alpha, \gamma$, and $\beta$, respectively. 
al. reported an individual with persistent hypermethioninemia who developed abnormal neurological symptoms and brain demyelination that responded favorably to AdoMet therapy (20). Another hypermethioninemic patient, identified by routine newborn screening, has also developed brain demyelination and is mentally retarded (13).

To further examine the relationship between isolated persistent hypermethioninemia and MAT I/III deficiency and whether brain demyelination may be a consequence of the disorder, we characterized the MATA1 gene of eight hypermethioninemic individuals, including the two patients with brain demyelination. All eight patients were found to contain mutations in the coding region of the MATA1 gene. The MATA1 genes of the two demyelination patients were homozygous for mutations that cause frame shifts in the coding region resulting in a truncated MAT $\alpha 1$ subunit devoid of enzymatic activity. Our results suggest that one essential role of MAT I/III is to maintain myelin structure in the brain.

\section{Methods}

Isolated persistent hypermethioninemic individuals. We have analyzed the MATA1 gene of eight individuals with isolated persistent hypermethioninemia. Patient G4 has been positively diagnosed as having reduced MAT activity in liver biopsy samples (16). Patient $\mathrm{C}$, who was diagnosed as having brain demyelination at age 11, has been extensively studied (20). The other six patients were identified by routine screening of newborns for hypermethioninemia as reported by Mudd et al. (13). Genomic DNA preparations from patients and the parents were extracted from blood samples. Genomic DNA from patient G4 was isolated from cultured skin fibroblasts kindly sent to us by Dr. Susan Sklower of the Institute for Basic Research in Developmental Disabilities, Staten Island, NY. The DNAs were isolated using a Nucleon II kit obtained from Scotlab (Strathclyde, Scotland). Peripheral-blood samples were obtained with the informed consent of the patients.

Analysis of the MATA1 gene by SSCP and DNA sequencing. The $M A T A 1$ gene was characterized by amplifying the coding regions of each of exons I to IX and the corresponding intron-exon junctions by PCR using nine pairs of oligonucleotide primers containing $5^{\prime}$-untranslated, $3^{\prime}$-untranslated and intron sequences of the MATA1 gene as previously described (19). The PCR amplified fragments, I (175 bp), II (164 bp), III (239 bp), IV (238 bp), V (263 bp), VI (330 bp), VII (292 bp), VIII (236 bp), and IX (201 bp), were analyzed for single strand conformation polymorphism (SSCP) (21) by electrophoresing wild-type and mutant target DNAs side by side through MDE nondenaturing gels (AT Biochem, Malvern, PA) following the protocols provided by the manufacturer. To increase the sensitivity of SSCP analysis, we also analyzed the amplified fragments on MDE gels containing 5\% glycerol. Potential mutations in the target DNA were visualized by the differential migration of one or both of the amplified strands. To confirm the presence of mutations, amplified fragments were subcloned into the pNoTA/T7 vector using the Prime PCR Cloning System $\left(5^{\prime}-3^{\prime}\right.$, Inc., Boulder, CO) and five or more subclones of each exon were sequenced. Direct sequencing was performed on exon V, VII, and VIII of patients C, 3, and 8, respectively, using a Cyclist $^{\mathrm{TM}} \mathrm{Exo}^{-}$Pfu DNA sequencing kit (Stratagene, Torrey Pines, CA).

Construction of MATA1 mutants. Mutants were constructed in the vector $\mathrm{pSVL}$ as described previously (19). The constructs were confirmed by sequence analysis and a BamHI fragment containing the entire mutant cDNA was isolated and subcloned into a bacterial expression vector, pQE30 (The QIAexpress System, QIAGEN Inc., Chatsworth, CA).

Antibody production and Western blot analysis. The pQEhMAT expression construct containing the entire coding region (nucleotides 1 to 1188) of human MATA1 cDNA in pQE30 was transformed into
M15 bacteria and expression of recombinant MAT was induced by the addition of $2 \mathrm{mM}$ isopropylthio- $\beta$-galactoside (IPTG). The recombinant protein containing a $6 \times$ His tag was purified on a nickel chelate Ni-NTA resin and used for antibody production in rabbits. For Western blot analyses, bacterial extracts were electrophoresed through $10 \%$ polyacrylamide denaturing gels and transferred to Immobilon P (Millipore, Marlborough, MA). The MAT $\alpha 1$ proteins in the extracts were detected using a rabbit anti-MAT $\alpha 1$ serum and either an alkaline phosphatase system or a chemiluminescence Lumi GLO Western blot kit (Kirkegaard and Perry Laboratories Inc., Gaithersburg, MD). The chemiluminescence blot was exposed for 5, 7 , and $10 \mathrm{~s}$ and the amount of MAT $\alpha 1$ proteins were quantified using a Macbeth TD932 densitometer.

Expression of MATa1 mutants in bacteria and COS-1 cells. M15 bacteria were transformed with wild-type or mutant $M A T A 1 \mathrm{cDNAs}$ in the $\mathrm{pQE} 30$ vector. Mock transfections with $\mathrm{pQE30}$ vector alone were used as controls. Cultures prepared from single colonies were grown for $3.5 \mathrm{~h}$ and induced with $2 \mathrm{mM}$ IPTG. After an additional $3.5 \mathrm{~h}$ growth, cells were harvested, resuspended in 1/10 volume of a buffer containing $50 \mathrm{mM} \mathrm{NaPO}_{4}, 0.3 \mathrm{M} \mathrm{NaCl}, 1 \mathrm{mg} / \mathrm{ml}$ lysozyme, and $1 \mathrm{mM}$ PMSF. After sonication and a clearing spin, the extracts were brought to $20 \%$ glycerol and analyzed for MAT activity.

Wild-type or mutant MATA1 cDNAs in the pSVL vector were transfected into COS-1 cells as previously described (19). Mock transfections of COS- 1 cultures with the pSVL vector were used as controls. After incubation at $37^{\circ} \mathrm{C}$ for $3 \mathrm{~d}$, the transfected cultures were homogenized in $0.3 \mathrm{ml}$ of a buffer containing $0.25 \mathrm{M}$ Tris- $\mathrm{HCl}, \mathrm{pH} 7.4$ and $4 \mathrm{mM} \beta$-mercaptoethanol and used for measuring MAT activity.

MAT activity was assayed essentially as described (8). Briefly, the enzyme was incubated for $30 \mathrm{~min}$ at $37^{\circ} \mathrm{C}$ in a reaction mixture $(100$ $\mu$ l) containing $0.1 \mathrm{M}$ Tris- $\mathrm{HCl}, \mathrm{pH} 8.2,20 \mathrm{mM} \mathrm{MgCl}_{2}, 150 \mathrm{mM} \mathrm{KCl}$, $10 \mathrm{mM}$ ATP, $5 \mathrm{mM} \beta$-merceptoethanol, and $500 \mu \mathrm{M} \mathrm{L}$-[methyl ${ }^{3} \mathrm{H}$ ] methionine $(0.5 \mu \mathrm{Ci}$, specific activity, $84 \mathrm{Ci} / \mathrm{mmol})$. The reaction was stopped with $10 \mu \mathrm{l}$ of $2 \mathrm{M} \mathrm{HClO}_{4}$ containing $5 \mathrm{mM}$ methionine. After centrifugation, $50 \mu \mathrm{l}$ of the supernatant solution was spotted onto a phosphocellulose circle, washed in $5 \mathrm{mM}$ methionine/1\% casamino acids, dried, and measured in a scintillation counter.

\section{Results}

The human MATA1 gene is located on the long arm of chromosome 10. The human MATA1 gene consists of 9 exons and 8 introns spanning approximately $20 \mathrm{~kb}$ (19). Genomic subclones containing exons II to IX of the MATA1 gene were used as probes for fluorescence in situ hybridization (FISH) analysis of metaphase chromosomes prepared from PHA stimulated peripheral blood lymphocytes. Specific hybridization was observed on the long arm of chromosome 10 and the location was confirmed by showing that a chromosome 10 centromere-specific probe (D10Z1) co-hybridized with the human MATA1 probe (Fig. 1). FISH analysis further located the MATA1 gene at $42 \%$ of the distance from the centromere to the telomere of chromosome arm 10q, a region that corresponds to band $10 \mathrm{q} 22$.

Identification of mutations in the MATA1 gene of hypermethioninemic individuals. In an earlier study, we showed that the MATA1 genes in three individuals with confirmed MAT I/ III deficiency contain mutations in the coding region of the gene (19). In the present study, we expanded our analysis to include a group of patients identified by routine screening of newborns for hypermethioninemia who have biochemical abnormalities compatible with MAT I/III deficiency (13) (Table I). Two patients in this group have developed demyelination of the brain $(13,20)$. An eighth individual, G4, has been positively diagnosed by enzyme assay as having MAT I/III defi- 

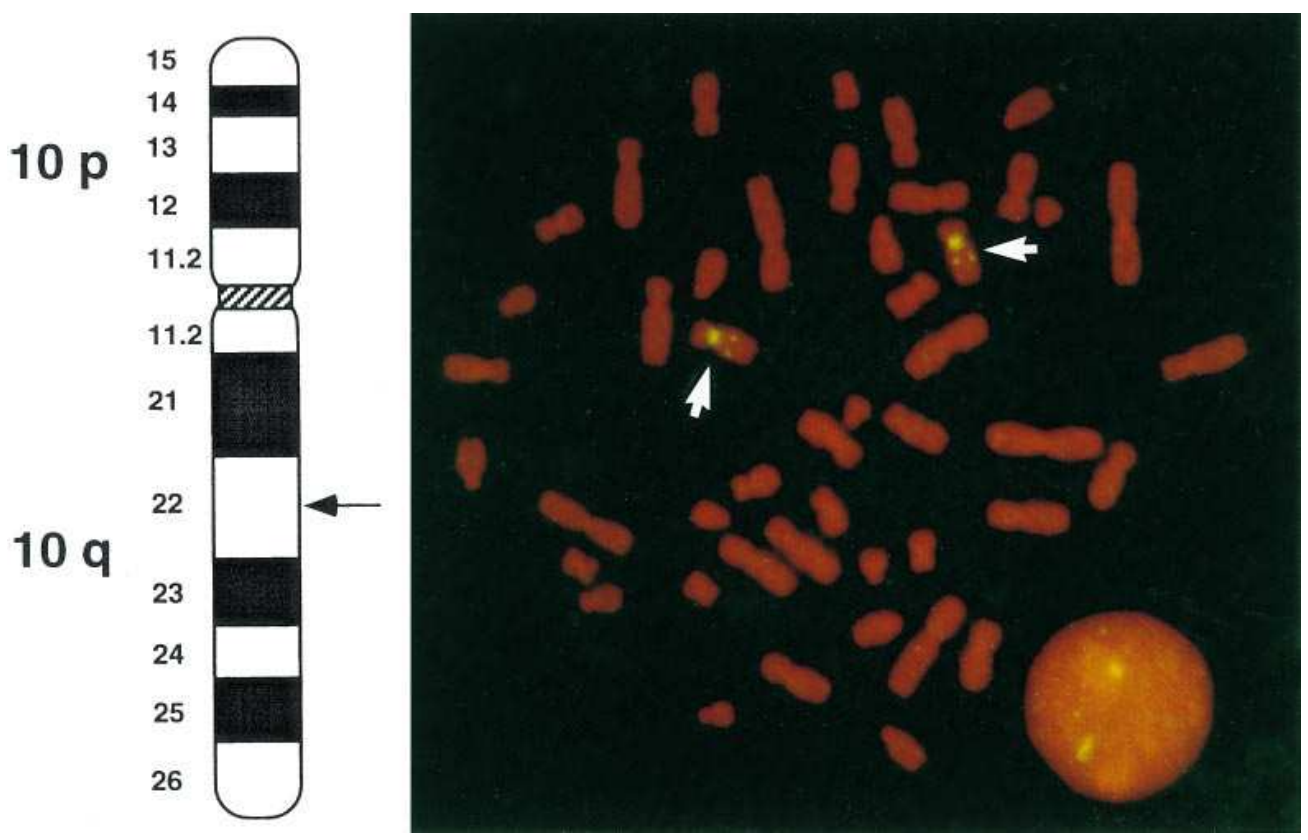

Figure 1. FISH localizes the human MATA1 gene to chromosome 10q22. A probe containing exons II-IX of the human MATA1 gene and a chromosome 10 centromere specific probe (D10Z1) are shown to cohybridize to human chromosome 10 by FISH (arrows).

ciency (16). All individuals reported here have plasma methionine concentrations at least 10 times higher than the upper limit of the reference range for normal adults $(\sim 35 \mu \mathrm{M})(\mathrm{Ta}-$ ble II). We screened this group of patients for mutations in the $M A T A 1$ gene to determine if uncomplicated high serum methionine concentration is a marker for MAT I/III deficiency and if the severe brain demyelination phenotype is associated with lesions in the gene. The four mutations previously identified, A55D, I322M, L305P, and P357L only partially inactivated MAT activity (19). Thus the phenotype of a complete
MAT I/III deficiency remained unknown. Exons I through IX and the associated intron-exon junctions of the MATAl gene of each patient were amplified individually. Potential mutations in the amplified fragments were scanned for by SSCP analysis on MDE gels in the absence (exon VI, VII, and VIII) or presence (exon V and IX) of glycerol (Fig. 2). The presence of mutations was confirmed by DNA sequencing.

SSCP analysis revealed the presence of potential mutations in the MATA1 gene of all eight individuals. The SSCP pattern of patient 3 suggested this patient is homozygous for a

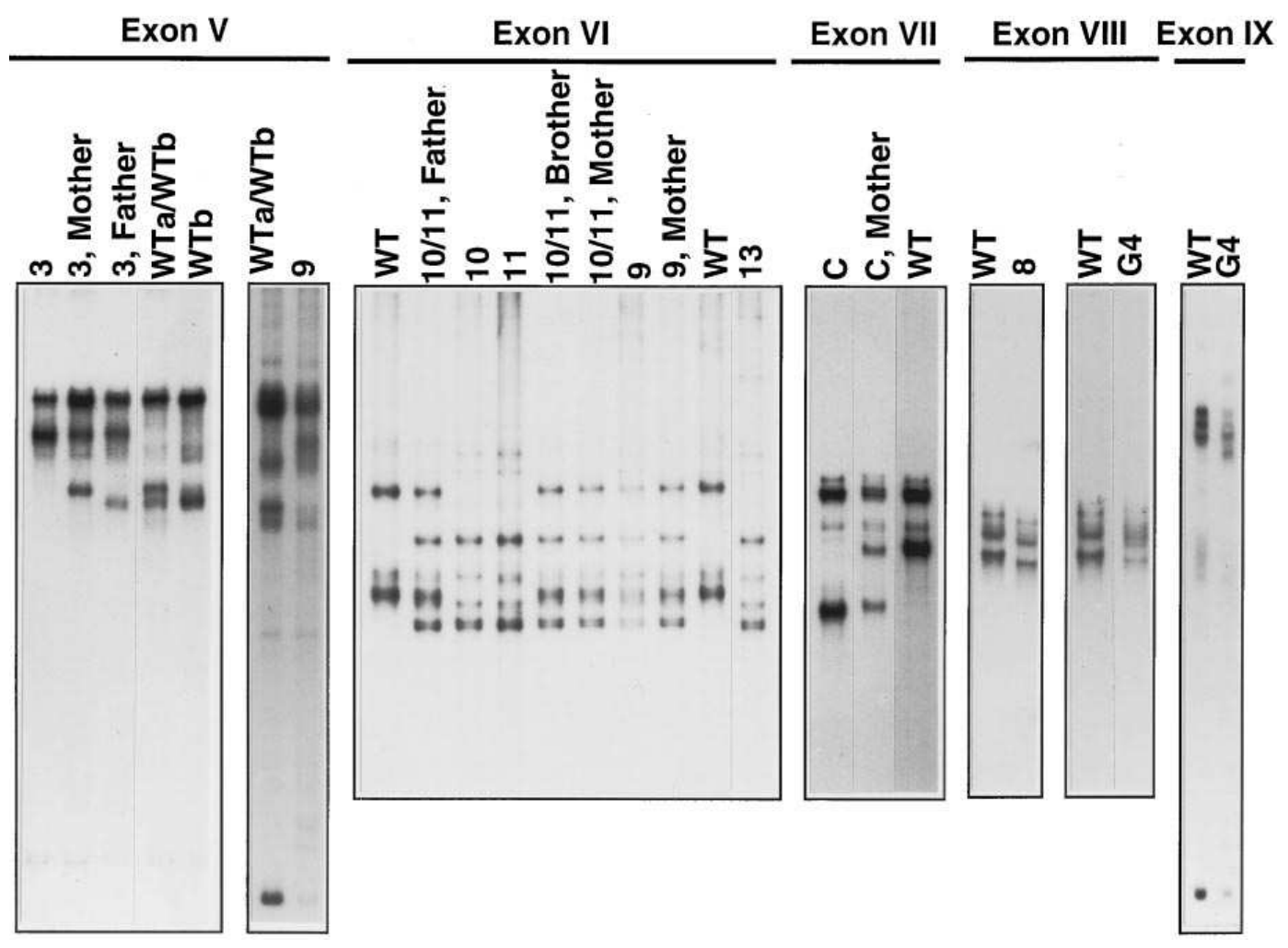

Figure 2. SSCP analysis of mutations in the MATA1 genes of individuals with isolated persistent hypermethioninemia. The exoncontaining fragments were amplified by PCR and analyzed by electrophoresis on MDE gels (exons VI, VII, and VIII) or MDE gels containing $5 \%$ glycerol (exons V and IX). 
Table I. Patients with Isolated Persistent Hypermethioninemia

\begin{tabular}{|c|c|c|c|c|}
\hline Patients* (sex) & $\mathrm{Age}^{\ddagger}$ & Mental status & $\begin{array}{l}\text { Neurological and/or } \\
\text { muscular status }\end{array}$ & Reference \\
\hline \multirow[t]{3}{*}{$\mathrm{C}(\mathrm{F})$} & 11 & IQ 87 & Dyspraxia & \\
\hline & & & Demyelination & \\
\hline & & & Calcification of basal ganglia & 20 \\
\hline $3(\mathrm{~F})$ & 4 & DQ 124 & Normal & 13 \\
\hline \multirow[t]{2}{*}{$8(\mathrm{~F})$} & 14 & Retarded & Dystonia & \\
\hline & & & Demyelination & 13 \\
\hline $9(\mathrm{M})$ & 1.8 & Normal & Normal & 13 \\
\hline $10(\mathrm{M})$ & 5.9 & IQ 111 & Normal & 13 \\
\hline $11(\mathrm{~F})$ & 9.6 & IQ 123 & Normal & 13 \\
\hline $13(\mathrm{~F})$ & 2.6 & DQ 105 & Normal & 13 \\
\hline $\mathrm{G} 4(\mathrm{~F})^{\S}$ & 0.7 & Normal & Normal & 16 \\
\hline
\end{tabular}

*Patient numbers are taken from the cited references. ${ }^{*}$ Age (years) at last report. ${ }^{\circledR}$ Confirmed MAT I/III deficiency.

potential mutation in exon $\mathrm{V}$ of the MATAl gene (Fig. 2). Both parents of patient 3 are heterozygous for the same exon $\mathrm{V}$ sequence change. Exon V of patient 3 and both parents was subcloned and five or more subclones of each were sequenced.
All exon $\mathrm{V}$ subclones of patient 3 had a TG insertion at nucleotide 539 (Fig. $3 A$ ). The two-basepair insertion alters the reading frame of the encoded protein and generates a stop at codon 185 . The predicted mutant MAT $\alpha 1$ is a severely truncated protein of 184 amino acids (Table II). Both parents of patient 3 are heterozygous for the 539insTG mutation. This observation was confirmed by direct sequencing (data not shown). In addition, a polymorphism in exon $\mathrm{V}$ of the gene was identified by SSCP (Fig. 2) and sequence analysis. Nucleotide 426 is either a T (WTa) or a C (WTb) (Fig. 2), both encode an Ala at codon 142. The mother of patient 3 has the $M A T A 1 * 426 \mathrm{~T}$ allele and the father has the $M A T A 1 * 426 \mathrm{C}$ allele (Fig. 2).

SSCP analysis of exon $\mathrm{V}$ of patient 9 showed that this patient has the same pattern as the father of patient 3 with the 539insTG mutation and the $M A T A 1 * 426 \mathrm{C}$ allele (Fig. 2), which was confirmed by DNA sequencing analysis. Three of the five exon $\mathrm{V}$ subclones of patient 9 contained the 539insTG mutation (Table II) and the other two subclones corresponded to the $M A T A 1 * 426 \mathrm{C}$ allele (data not shown). The mutation found in exon $\mathrm{V}$ may arise by duplication of a TG repeat caused by template-directed misalignment during replication (22).

Patient 9 also appeared to be heterozygous for a mutation in exon VI by SSCP analysis (Fig. 2). Four of the six exon VI

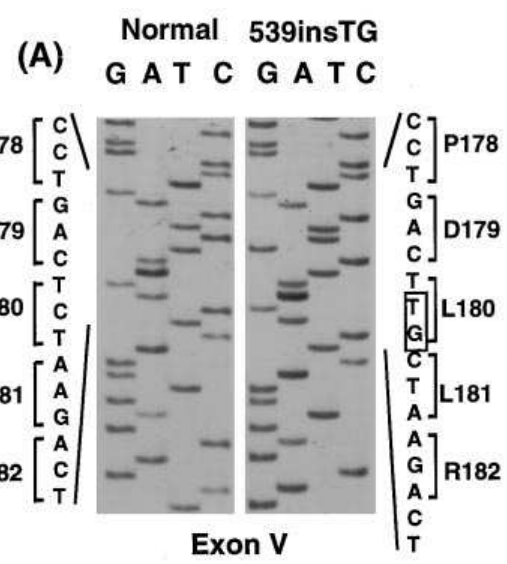

(D)
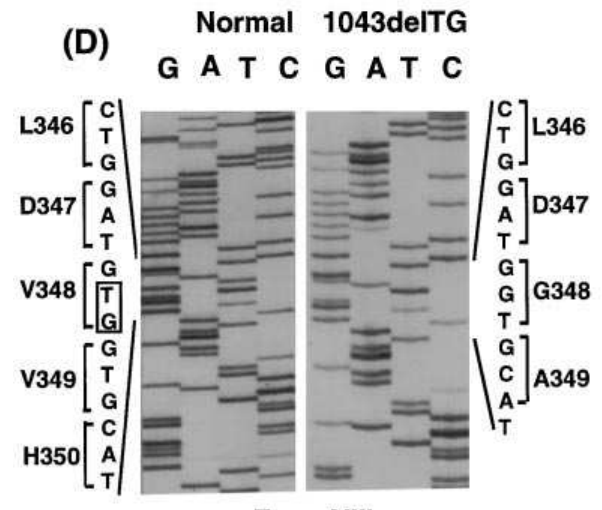

Exon VIII
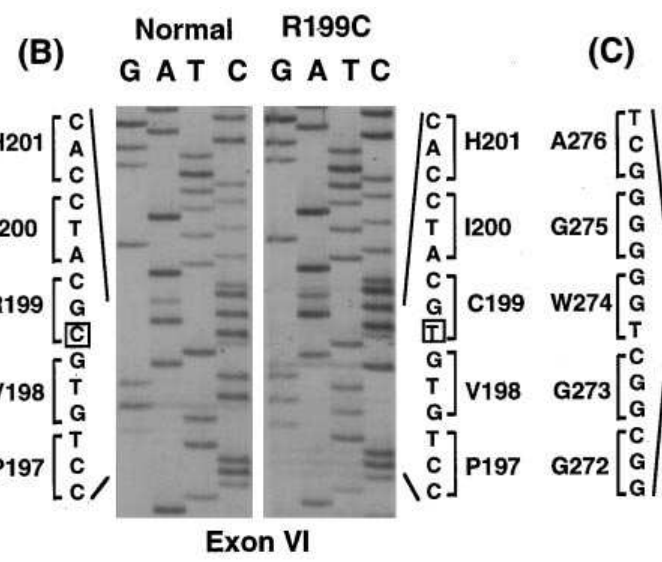

Normal 827insG
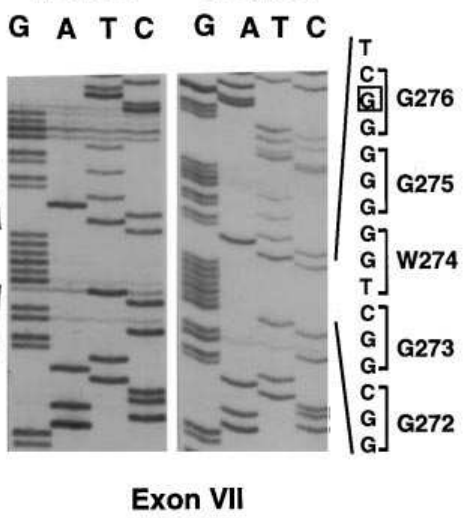

\section{(E)}

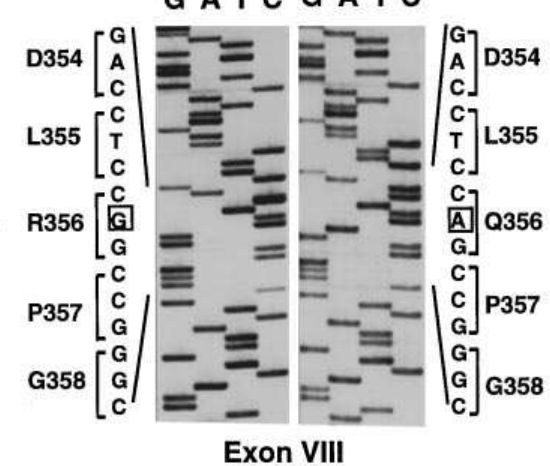

(F)

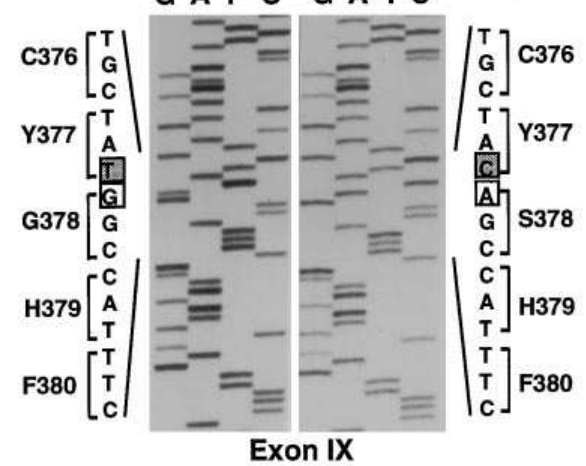

Figure 3. Autoradiograms of Sanger nucleotide sequencing reactions of the MATA1 gene from a normal individual and MAT I/III deficient patients. (A) Insertion of TG (boxed) at nucleotide 539 in exon V that generates a stop at codon 185. (B) $\mathrm{C}$ to $\mathrm{T}$ (boxed) transition at nucleotide 595 in exon VI that converts Arg-199 to a Cys (R199C). (C) Insertion of G (boxed) at nucleotide 827 in exon VII that generates a stop at codon 351. (D) Deletion of TG at nucleotides 1043-1044 in exon VIII that generates a stop at codon 350. (E) G to A transition at nucleotide 1067 in exon VIII that converts Arg-356 to a Gln (R356Q). (F) G to A transition at nucleotide 1132 in exon IX that converts Gly-378 to a Ser (G378S). A polymorphism, $1131 \mathrm{C} / \mathrm{T}$, is boxed and shaded. 
Table II. Mutations in the MATA1 Gene of Patients with Isolated Persistent Hypermethioninemia and Corresponding Enzymatic Activity

\begin{tabular}{|c|c|c|c|c|c|c|}
\hline Patient & $\begin{array}{l}\text { Allele } 1 \\
\text { Allele } 2\end{array}$ & Exon & Mutation & MAT Activity* & Relative ${ }^{\ddagger}$ MAT Activity & Plasma $^{\S}$ Methionine \\
\hline \multirow[t]{2}{*}{$\mathrm{C}$} & 827insG & VII & $351 X$ & 0.0 & & \\
\hline & 827insG & VII & $351 X$ & 0.0 & & $600-1,400$ \\
\hline \multirow[t]{2}{*}{3} & 539insTG & V & $185 \mathrm{X}$ & N.D. & & \\
\hline & 539insTG & V & $185 \mathrm{X}$ & N.D. & & $686-2541$ \\
\hline \multirow[t]{2}{*}{8} & 1043delTG & VIII & $350 \mathrm{X}$ & 0.0 & & \\
\hline & 1043delTG & VIII & $350 \mathrm{X}$ & 0.0 & & $1114-1629$ \\
\hline \multirow[t]{2}{*}{9} & 539insTG & $\mathrm{V}$ & $185 \mathrm{X}$ & N.D. & & \\
\hline & $595 \mathrm{CGC} \rightarrow \mathrm{TGC}$ & VI & R199C & $0.92 \pm 0.02$ & $11.1 \%$ & $759-1467$ \\
\hline \multirow[t]{2}{*}{10} & $595 \mathrm{CGC} \rightarrow \mathrm{TGC}$ & VI & R199C & $0.92 \pm 0.02$ & $11.1 \%$ & \\
\hline & $595 \mathrm{CGC} \rightarrow \mathrm{TGC}$ & VI & R199C & $0.92 \pm 0.02$ & $11.1 \%$ & $484-742$ \\
\hline \multirow[t]{2}{*}{11} & $595 \mathrm{CGC} \rightarrow \mathrm{TGC}$ & VI & R199C & $0.92 \pm 0.02$ & $11.1 \%$ & \\
\hline & $595 \mathrm{CGC} \rightarrow \mathrm{TGC}$ & VI & R199C & $0.92 \pm 0.02$ & $11.1 \%$ & $374-902$ \\
\hline \multirow[t]{2}{*}{13} & $595 \mathrm{CGC} \rightarrow \mathrm{TGC}$ & VI & R199C & $0.92 \pm 0.02$ & $11.1 \%$ & \\
\hline & $595 \mathrm{CGC} \rightarrow \mathrm{TGC}$ & VI & R199C & $0.92 \pm 0.02$ & $11.1 \%$ & $451-758$ \\
\hline \multirow[t]{2}{*}{ G4 } & $1067 \mathrm{CGG} \rightarrow \mathrm{CAG}$ & VIII & R356Q & $6.43 \pm 0.44$ & $53.1 \%$ & \\
\hline & $1132 \mathrm{GGC} \rightarrow \mathrm{AGC}$ & IX & G378S & $0.19 \pm 0.01$ & $0.17 \%$ & $254-400$ \\
\hline
\end{tabular}

*MAT activity (nmol/min/mg protein) from bacterially expressed wild-type and mutant MATA1 cDNA was presented as the mean \pm SEM. Mock MAT activity has been subtracted from each sample. N.D., not determined. The amounts of MAT Activity in wild-type cDNA transformed and mock bacterial cultures were $16.55 \pm 0.56$ and $0.17 \pm 0.01$, respectively. ${ }^{\ddagger}$ Relative MAT activity represents percent of wild-type MAT activity normalized to the amounts of MAT $\alpha 1$ protein in each bacterially expressed sample as determined by Western blot analysis using a chemiluminescence Lumi GLO Western blot kit. ${ }^{\S}$ Plasma methionine $(\mu \mathrm{M})$ levels previously published in references listed in Table I.

subclones had a base change in codon 199 (CGC $\rightarrow$ TGC), resulting in an Arg $\rightarrow$ Cys (R199C) mutation, transmitted from the mother (Fig. 2 and Fig. 3 B). Thus patient 9 is a compound heterozygote with two mutant alleles, 539insTG and R199C.

SSCP analysis also revealed that the MATA1 gene of patients 10 and 11 , who are brother and sister, and patient 13 , who is unrelated, is homozygous for the R199C mutation in exon VI (Fig. 2 ). The parents and brother of patients 10 and 11, like the mother of patient 9, had an SSCP pattern consistent with heterozygosity for the R199C mutation (Fig. 2). The sequence of all exon VI subclones of patients 10,11 , and 13 have the $\mathrm{C}$ to $\mathrm{T}$ transition at nucleotide 595, resulting in the R199C mutation (Fig. 3 B). This analysis demonstrates that all three patients are homozygous for R199C and that patients 10 and 11 inherited one mutant allele from each parent. Methylation of a $\mathrm{CpG}$ doublet, a hotspot for mutation in bacteria and eukaryotes, may be responsible for the $\mathrm{C}$ to $\mathrm{T}$ transition observed in these patients (23).

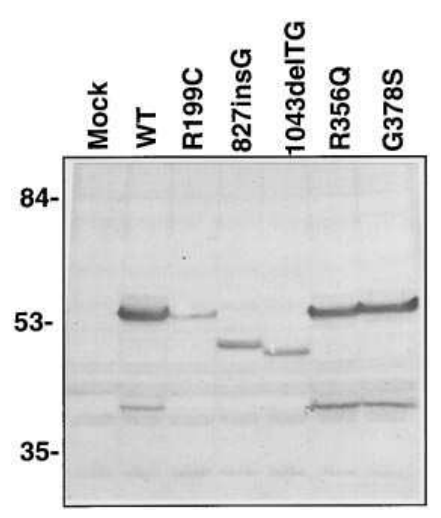

Figure 4. Western blot analysis of bacterially expressed MAT $\alpha 1$ protein. $50 \mu l$ of each bacterial extract was electrophoresed through $10 \%$ polyacrylamide denaturing gels, transferred to Immobilon $P$, and MAT $\alpha 1$ protein detected by an alkaline phosphatase system. Numbers at left indicate sizes of protein markers, in $\mathrm{kD}$.
SSCP analysis suggested that patient $\mathrm{C}$, who manifested brain demyelination at age 11 years (20), is homozygous for a potential mutation in exon VII (Fig. 2). The mother is heterozygous for the same change. Sequence analysis revealed that all five exon VII subclones of patient $\mathrm{C}$ had a $\mathrm{G}$ insertion at nucleotide 827 (Fig. $3 C$ ), which was confirmed by direct sequence analysis (data not shown). The $G$ insertion alters the reading frame of the encoded protein and generates a stop at codon 351 . The predicted mutant MAT $\alpha 1$ is a truncated protein of 350 amino acids (Table II).

The clinical manifestations of patient 8 include brain demyelination, dystonia, and mental retardation (13). SSCP analysis revealed that patient 8 is homozygous for a potential mutation in exon VIII (Fig. 2). All subclones sequenced indicated that nucleotides 1043 (T) and 1044 (G) were deleted (Fig. 3 D). The deletion in exon VIII was further confirmed by direct sequencing (data not shown). The two-basepair deletion alters the reading frame of the encoded protein and generates a stop at codon 350. The predicted mutant MAT $\alpha 1$ is a truncated protein of 349 amino acids (Table II).

Patient G4 has been positively diagnosed as having MAT I/ III deficiency (16) and SSCP analysis revealed potential mutations in exons VIII and IX (Fig. 2). Sequence analysis indicated that five of the ten exon VIII subclones contained a $\mathrm{G}$ to A transition at nucleotide 1067 that converts $\mathrm{Arg} \rightarrow \mathrm{Gln}$ at codon 356 (R356Q) (Fig. 3 E). Three of the five exon IX subclones contained a $\mathrm{G}$ to A transition at nucleotide 1132 that converts Gly $\rightarrow$ Ser at codon 378 (G378S) (Fig. 3 F). Our findings suggest that patient G4 is a compound heterozygote (Table II).

The severely truncated MAT $\alpha 1$ of 184 residues generated by the 539insTG mutation is expected to be enzymatically inactive. However, MAT $\alpha 1$ mutants of 350 and 349 amino acids generated by the 827 insG and 1043 delTG mutations, respec- 
tively, may be enzymatically active. We therefore constructed cDNA clones which contain the 827insG and 1043delTG mutations as well as cDNAs that contain each of the three observed point mutations, R199C, R356Q, and G378S. All mutated cDNAs were subcloned into pQE30 and pSVL, expressed in E. coli (pQE30 constructs) and COS- 1 cells (pSVL constructs), and their enzymatic activities determined. Similar results were obtained with both systems. However, MAT activity obtained in the bacterial system (Table II) was 6-7-fold higher than that obtained in COS-1 cells (data not shown). Western blot analysis was performed to demonstrate that the wild type and mutant constructs directed the synthesis of the MAT $\alpha 1$ protein (Fig. 4). The MAT $\alpha 1$ proteins detected by chemiluminescence in a duplicate blot were used to quantify the relative amounts of enzyme proteins. The $827 \mathrm{insG}$ and $1043 \mathrm{delTG}$ mutants had no detectable MAT enzymatic activity (Table II). The G378S mutant retained only $0.17 \%$ of wild-type activity (Table II). On the other hand, the R199C and R356Q mutants retained 5.1 and $53.1 \%$ of wild-type activity, respectively (Table II).

\section{Discussion}

We have previously reported the characterization of the human MATA1 gene and established a correlation between mutations in the gene and MAT I/III deficiency (19). In the present study, we have mapped the single copy MATA1 gene to human chromosome 10q22. The highly homologous $M A T A 2$ gene has been localized to human chromosome 2p11.2 (12). We have extended our studies by analyzing the MATA1 gene of seven individuals (and the available parents) diagnosed simply by high serum methionine levels as well as one additional subject with confirmed MAT I/III deficiency as demonstrated by enzyme assay in liver biopsies. The MATA1 gene of all eight individuals contained mutations and a total of six new mutations, 539insTG, R199C, 827insG, 1043delTG, R356Q, and G378S, were uncovered. All six mutations reduced or abolished MAT activity and the associated hypermethioninemic phenotype was transmitted in an autosomal recessive manner. The correlation between isolated persistent hypermethioninemia and deleterious mutations in the MATA1 gene demonstrates that high serum methionine in the absence of hyperhomocyst(e)inemia, tyrosinemia, or serious liver disease is a valid indicator of MAT I/III deficiency. Furthermore, we observe a rough inverse correlation between residual MAT activity and the plasma methionine level (Table II).

The mutations previously identified in the MATA1 gene of three patients with confirmed MAT I/III deficiency only partially inactivate the enzyme. These patients are relatively free of major clinical difficulties. In the present study, four patients (10, 11, 13, and G4) also have MATA1 gene mutations (R199C, R356Q, and G378S) that only partially inactivate the enzyme. These patients are also clinically well at this time. It appears that low levels of MAT I/III activity are sufficient to maintain clinical well-being, at least for the first few decades of life.

Although many hypermethioninemic individuals have no severe clinical manifestations, two such individuals, patients $\mathrm{C}$ and 8 , were found to suffer demyelination at age 11 years (13, $20)$. Before the diagnosis of demyelination, patient $\mathrm{C}$ also developed fine nystagmus, dysdiadochokinesis, and increased tendon reflexes (20) and patient 8, who is mentally retarded, suffers from dystonia and dysmetria (13). The involvement of
MAT I/III in the maintenance of myelin structure was indicated by observations that the demyelination process in patient $\mathrm{C}$ was reversed by treatment with AdoMet, the product of MAT (20). SSCP and DNA sequencing analyses revealed that the MATA1 gene of both patients contains mutations that result in truncated MAT $\alpha 1$ subunits of 350 (patient C) and 349 (patient 8) amino acids. In vitro expression studies demonstrated that both truncated proteins are devoid of MAT activity. Therefore a complete lack of MAT I/III activity puts an individual at risk for development of brain demyelination. Patient 3 is also homozygous for a mutation in the MATA1 gene that is predicted to encode a severely truncated enzyme subunit of 184 amino acids. Patient 3, who is still young (4 years of age), appears to be at risk for development of this brain disorder in the absence of any preventative measures.

These observations raise the question of why a lack of MAT I/III should lead to a demyelination process in the brain. Myelin, which is concentrated in the white matter of the mammalian brain, spinal cord and peripheral nerves, consists of 15$30 \%$ protein and $70-85 \%$ lipid (24). Over $40 \%$ of the myelin lipid is phospholipid that contains high levels of phosphatidylcholine and sphingomyelin. Since AdoMet is the major methyl donor for most biologically important methylation reactions, we speculate that methylated compounds synthesized in the liver in AdoMet-dependent reactions are essential for maintenance of myelin structure. Indeed, the liver synthesizes at least $90 \%$ of the endogenously formed phosphatidylcholine from phosphatidylethanolamine and AdoMet (25). Phosphatidylcholine is also a precursor in the biosynthesis of sphingomyelin (26). Phosphatidylcholine synthesized in the liver is exported to the serum where it is degraded to choline (27), and together with ingested choline, can be taken up by the brain to be incorporated into myelin phosphatidylcholine (28). Another methylated compound of interest is creatine, formed by the AdoMetdependent methylation of guanidinoacetate (29). Although the vast majority of creatine is contained in muscles, the brain requires creatine and possesses a specific uptake system (30). Deficiency of brain creatine has been associated with severe neurological manifestations (31). Although creatine deficiency in muscle and/or brain has not yet been reported among hypermethioninemic individuals, such a deficiency would be a potential risk for these patients.

A puzzling aspect of our observations is that demyelination was diagnosed in the two patients with null MATA1 gene mutation only at age 11 years. This suggests that MAT II, synthesized in nonhepatic tissues as well as in low amounts in the liver, is able to sustain the synthesis of an adequate amount of phosphatidylcholine and sphingomyelin for some time during postnatal development. Dietary intake of choline and creatine may also help to maintain myelin structure in MAT I/III deficient individuals. Myelination is a long term process (32) and the choline components of myelin are constantly being lost from and replenished to the brain (33). Moreover, choline uptake by the brain apparently decreases with age (34), suggesting an increased plasma choline concentration may be required as aging progresses.

If demyelination manifested by MAT I/III deficient patients is indeed caused by the lack of synthesis of AdoMetdependent methylated products, then exogenous administration of choline may be useful for the treatment of this disorder. Administration of creatine, in addition to choline, may be advantageous because creatine feedback inhibits the synthesis of its precursor, guanidinoacetate (29), thereby sparing AdoMet 
for the synthesis of other methylated compounds. Both choline and creatine have been given to humans without serious side effects or toxicity $(31,34)$. A more efficacious therapy may be to provide the missing product of MAT reaction, AdoMet, which has been shown to cause re-myelination in patient $C(20)$.

An important finding emerging from this study is that isolated persistent hypermethioninemia is not benign. The lesions in these individuals should be specially diagnosed early in life by DNA-based testing in order to prevent potential neurological manifestations.

\section{Acknowledgments}

We thank Drs. G.L. Cantoni and R. Surtees for helpful discussions concerning the mechanisms of brain demyelination.

\section{References}

1. Cantoni, G.L. 1953. S-Adenosylmethionine: a new intermediate formed enzymatically from L-methionine and adenosinetriphosphate. J. Biol. Chem. 204:403-416.

2. Kotb, M., and A.M. Geller. 1993. Methionine adenosyltransferase: structure and function. Pharmac. Ther. 59:125-143.

3. Mudd, S.H., H.L. Levy, and F. Skovby. 1994. Disorders of transsulfuration. In The Metabolic Basis of Inherited Diseases. C.R. Scriver, A.L. Beaudet, R. Charles, W.S. Sly, D. Valle, editors. McGraw-Hill Inc, New York. 1279-1327.

4. Okada, G., H. Teraoka, and K. Tsukada. 1981. Multiple species of mammalian S-adenosylmethionine synthetase. Partial purification and characterization. Biochemistry. 20:934-940.

5. Sullivan, D.M., and J.L. Hoffman. 1983. Fractionation and kinetic properties of rat liver and kidney methionine adenosyltransferase isozymes. Biochemistry. 22:1636-1641.

6. Cabrero, C., J. Puerta, and S. Alemany. 1987. Purification and comparison of two forms of S-adenosyl-L-methionine synthetase from rat liver. Eur. J. Biochem. 170:299-304.

7. Kotb, M., and N.M. Kredich. 1985. S-Adenosylmethionine synthetase from human lymphocytes. Purification and characterization. J. Biol. Chem. 260: 3923-3930.

8. Mitsui, K., H. Teraoka, and K. Tsukada. 1988. Complete purification and immunochemical analysis of S-adenosylmethionine synthetase from bovine brain. J. Biol. Chem. 263:11211-11216.

9. Alvarez, L., F. Corrales, A. Martin-Duce, and J.M. Mato. 1993. Characterization of a full-length cDNA encoding human liver S-adenosylmethionine synthetase: tissue-specific gene expression and mRNA levels in hepatopathies. Biochem. J. 293:481-486.

10. Sakata, S.F., L.L. Shelly, S. Ruppert, G. Schutz, and J.Y. Chou. 1993. Cloning and expression of murine S-adenosylmethionine synthetase. J. Biol. Chem. 268:13978-13986.

11. Horikawa, S., and K. Tsukada. 1992. Molecular cloning and developmental expression of a human kidney S-adenosylmethionine synthetase. FEBS Lett. 312:37-41.

12. De La Rosa, J., J. Ostrowski, M.M. Hryniewicz, N.M., Kredich, M. Kotb, H.L. LeGros, Jr., M. Valentine, and A.M. Geller. 1995. Chromosomal localization and catalytic properties of the recombinant $\alpha$ subunit of human lymphocyte methionine adenosyltransferase. J. Biol Chem. 270:21860-21868.

13. Mudd, S.H., H.L. Levy, A. Tangerman, C. Boujet, N. Buist, A. David-
son-Mundt, L. Hudgins, K. Oyanagi, M. Nagao, and W.G. Wilson. 1995. Isolated persistent hypermethioninemia. Am. J. Hum. Genet. 57:882-892.

14. Gaull, G.E., and H.H. Tallan. 1974. Methionine adenosyltransferase deficiency: new enzymatic defect associated with hypermethioninemia. Science (Wash. DC).186:59-60.

15. Finkelstein, J.D., W.E. Kyle, and J.J. Martin. 1975. Abnormal methionine adenosyltransferase in hypermethioninemia. Biochem. Biophys. Res. Commun. 66:1491-1497.

16. Gaull, G.E., H.H. Tallan, D. Lonsdale, H. Przyrembel, F. Schaffner, and D.B. Von Bassewitz. 1981. Hypermethioninemia associated with methionine adenosyltransferase deficiency: clinical, morphological and biochemical observations on four patients. J. Pediatr. 98:734-741.

17. Gahl, W.A., J.D. Finkelstein, K.D., Mullen, I. Bernardini, J.J. Martin, P. Backlund, K.G. Ishak, J.H. Hoofnagle, and S.H. Mudd. 1987. Hepatic methionine adenosyltransferase deficiency in a 31-year-old man. Am. J. Hum. Genet. 40:39-49.

18. Gout, J.-P., J.-C Serre, M. Dieterlen, I. Antener, P. Frappat, M. Bost, and A. Beaudoing. 1977. Une nouvelle cause d'hypermethioninemie de l'enfant: Le deficit en S-adenosyl-methionine-synthetase. Arch. Fr. Pediatr. 34:416-423.

19. Ubagai T., K.-J. Lei, S. Huang, S.H. Mudd, H.L. Levy, and J.Y. Chou. 1995. Molecular mechanisms of an inborn error of methionine pathway: methionine adenosyltransferase deficiency. J. Clin. Invest. 96:1943-1947.

20. Surtees, R., J. Leonard, and S. Austin. 1991. Association of demyelination with deficiency of cerebrospinal-fluid S-adenosylmethionine in inborn errors of methyl-transfer pathway. Lancet. 338:1550-1554.

21. Orita, M, H. Iwahana, H., Kanazawa, K. Hayashi, and T. Sekiya. 1989. Detection of polymorphisms of human DNA by gel electrophoresis as singlestrand conformation polymorphisms. Proc. Natl. Acad. Sci. USA. 86:2766-2770.

22. Ripley, L.S. 1990. Frameshift mutation: determinants of specificity. Annu. Rev. Genet. 24:189-213.

23. Holliday, R., and G.W. Grigg. 1993. DNA methylation and mutation. Mut. Res. 285:61-67.

24. Norton, W.T., and W. Cammer. 1984. Isolation and characterization of myelin. In Myelin. P. Morell, editor. Plenum Press, New York. 147-195.

25. Ridgway, N.D. 1989. Phosphatidylethanolamine N-methyltransferase. In Phosphatidylcholine Metabolism. D.E. Vance, editor. CRC Press, Inc., Boca Raton, FL. 103-120.

26. Spence, M.W. 1989. Sphingomyelin biosynthesis and catabolism. In Phosphatidylcholine Metabolism. D.E. Vance, editor. CRC Press, Inc., Boca Raton, FL. 185-203.

27. Bremer, J., K. Norum, and P. Bjornstad. 1986. Biochemistry of methylated phospholipids. In Biological Methylation and Drug Design. Experimental and Clinical Role of S-Adenosylmethionine. R.T. Borchardt, C.R. Creveling, P.M. Ueland, editors. Humana Press, Totowa, NJ. 55-66.

28. Klein, J., A. Koppen, K. Loffelholz, and J. Schmitthenner. 1992. Uptake and metabolism of choline by rat brain after acute choline administration. $J$. Neurochem. 58:870-876.

29. Walker, J.B. 1979. Creatine: biosynthesis, regulation, and function. $A d v$. Enzymol. 50:177-242.

30. Guimbal, C., and M.W. Kilimann. 1993. A $\mathrm{Na}^{+}$-dependent creatine transporter in rabbit brain, muscle, heart, and kidney. cDNA cloning and functional expression. J. Biol. Chem. 268:8418-8421.

31. Stockler, S., D. Isbrandt, F. Hanefeld, B. Schmidt, and K. von Figura 1996. Guanidinoacetate methyltransferase deficiency: the first inborn error of creatine metabolishm in man. Am. J. Hum. Genet. 58:914-922.

32. Volpe, J.J. 1995. Neuronal proliferation, migration, organization, and myelination. In Neurology of the Newborn. W.B. Saunders Co., Philadelphia, PA. 43-92.

33. Chiba, N., and T. Arakawa. 1971. Metabolism of phosphatidylcholine in brain and liver of developing rats. Tohoku J. Exp. Med. 104:359-371.

34. Cohen, B.M., P.F. Renshaw, A.L. Stoll, R.J. Wurtman, D. YurgelunTodd, and S.M. Babb. 1995. Decreased brain choline uptake in older adults. An in vivo proton magnetic resonance spectroscopy study. JAMA. 274:902-907. 